\title{
USING GIS-BASED MULTI-CRITERIA DECISION ANALYSIS TECHNIQUES IN THE SMART CITIES
}

\author{
S. Sisman ${ }^{1}$, A.C. Aydinoglu ${ }^{2 *}$ \\ ${ }^{1}$ Dept. of Geomatics Engineering, Gebze Technical University, 41400 Gebze, Kocaeli, Turkey - ssisman@gtu.edu.tr \\ ${ }^{2}$ Dept. of Geomatics Engineering, Gebze Technical University, 41400 Gebze, Kocaeli, Turkey - aydinoglu@gtu.edu.tr
}

\author{
Commission VI, WG VI/4
}

KEY WORDS: Geography Information Systems (GIS), Multi Criteria Decision Analysis (MCDA), Smart Cities

\begin{abstract}
:
The population of cities is increasing rapidly nowadays, and therefore, rational use of urban resources is required. With developing technology, the amount of data obtained from different sources also increases. This situation sometimes causes complex geographic decision problems in cities where many factors must be evaluated simultaneously. Difficulties in this decision-making process can be overcome by using Multi-Criteria Decision Analysis (MCDA) techniques. In this study, how the different MCDA techniques can be used in geographic-based problems and the most commonly used methods were examined in this context. The case applications on the adaptation of GIS-based MCDA techniques in smart cities were examined and explained. All of the examined case applications were carried out in the Pendik district of Istanbul. The subjects of the investigated case applications are, respectively, the evaluation of land suitability for determining urban development areas, producing a land value map for the management of the urban real estate, parking areas selection for sustainable urban transportation planning, and prioritizing suitable/alternative car parking areas. This study provides an effective implementation methodology for the hybrid use of GIS-based MCDA techniques within the scope of sustainable urban land management practices in smart cities.
\end{abstract}

\section{INTRODUCTION}

Multi-Criteria Decision Analysis (MCDA) is a set of systematic procedures for analysing complex decision problems. It aims to establish a connection by dividing the decision problem into small, simple, and understandable parts so that a meaningful result can be obtained from these parts (Malczewski, 1999). MCDA are used as a decision-support system for the problems where conflicting economic, environmental, social, technical objectives are involved (De Montis, 2000). There are many MCDA techniques in literature and are more widely used today. Some of these techniques are as follows (Cinelli et al., 2014; Huang et.al., 2011; Nyimbili and Erden, 2020): Analytic Hierarchy Process (AHP), Technique for Order Preference by Similarity to Ideal Solution (TOPSIS), Preference Ranking Organization METHod for Enrichment of Evaluations (PROMETHEE), VlseKriterijumska Optimizacija I Kompromisno Resenje (VIKOR), Weighted Linear Combination (WLC), Fuzzy Logic, Ordered Weighted Averaging (OWA), Evaluation Based on Distance from Average Solution (EDAS), COmplex PRoportional ASsessment (COPRAS), Combinative Distance-based ASsessment (CODAS), Simple Multi-Attribute Rating Technique (SMART), Multi-Attribute Utility Theory (MAUT), and CRiteria Importance Through Intercriteria Correlation (CRITIC), DEcision MAking Trial and Evaluation Laboratory (DEMATEL) and Entropy Technique. Besides, some of these techniques have fuzzy logic-based use, such as Fuzzy AHP (FAHP), Fuzzy TOPSIS (FTOPSIS), and Fuzzy VIKOR (FVIKOR). The common goal of all of these techniques is to systematically determine the optimum decision among many alternative decisions based on different criteria.
Geography Information Systems (GIS) technology is widely recognized for its capability in performing geographic analysis, which is designed to manipulate and manage spatial data in various thematic applications (Wang et al., 2009). In other words, GIS is a information technology for collecting, storing, manipulating, analyzing, and presenting geographic datasets to obtain information for reasonable decision making (Malczewski and Rinner, 2015). On the other hand, there is a synergy between MCDA techniques and GIS around for more than 20 years. The integrated use of GIS and MCDA can be considered as a process that transforms and combines geographic data and decision-makers' preferences to obtain information in decision making (Malczewski, 2006; Malczewski and Rinner, 2015). GIS-based MCDA techniques enhance the complex geographic decision-making processes and present a systematic methodology to decision-makers, because of the capability of evaluating a large number of parameters simultaneously for decision making (Malczewski, 2010).

The use of GIS and different MCDA approaches may vary according to requirements of application areas. For example, while AHP and WLC techniques can be preferred in the fire station site selection problem by decision-makers, Fuzzy Logic techniques including FAHP can be preferred to provide land value information. Besides GIS-based flexible use of MCDA techniques, there are various application areas. Applications related to this integrated usage in the literature are as follows in the general context. Different facility site selection applications, which are of great importance for people living in the city and urban resources such as car parking area, school, hospital, shopping mall, fire station, solid waste landfill and so on, determining the most suitable lands for solar and wind power plant projects in ensuring effective use planning of natural

\footnotetext{
* Corresponding author
} 
energy resources, management of natural disasters such as floods, landslides, and earthquakes, urban planning studies for the rational use of urban land resources, real estate valuation and smart real estate management applications, prioritizing alternative urban investment projects, suitability analysis according to the use decisions of different land uses, agricultural land suitability analysis for different agricultural products as well as have many other application areas. As can be understood from the above mentioned, the use of different MCDA techniques with GIS offers an extremely wide range of geographic application tools. The use of these techniques in smart cities has a very important place, as well as a requirement for efficient smart city management decisions.

With the increasing data density coming from different sources, it is necessary to manage the information in a rational and timely manner in order to ensure better management of urban resources. This points to the necessity of using GIS technology and MCDA techniques in smart cities. Therefore, in this study, it is aimed to examine MCDA techniques in GIS applications including smart cities.

This paper's main objective is to develop an effective methodology in decision-making applications for smart cities by utilizing GIS and MCDA techniques. The structure of this paper is organized as follows: Section 2 explains in detail the MCDA techniques the most used in the literature on different decision problems. In section 3, case studies conducted with GIS-based MCDA techniques in the Pendik district of Istanbul province were examined. Namely, the authors focused on their own background research to examine some methods in detail. Finally, in section 4, the results of the study were discussed and recommendations were given for future studies.

\section{MCDA TECHNIQUES}

As mentioned in the introduction section, although there are different MCDA techniques, some of these methods have been applied more in practice. AHP, Fuzzy Logic, WLC, TOPSIS and VIKOR are among these methods. On the other hand, also fuzzy logic-based methods such as FAHP are among the most preferred techniques in the literature (Nadaban et.al, 2016). While some of these techniques are used to weight the criteria that affect the decision in the decision-making process, some are used in prioritizing/ranking alternative decision points, and some are used in combining the results of the geographic analysis.

The AHP method proposed by Saaty has been one of the most preferred methods of the MCDA in different geographic applications due to the mathematical convenience. It provides in the calculation of the relative weight coefficients of the criteria and its integration into GIS is easy (Mardani et al., 2015). AHP involves three main steps, including decomposition of the problem, pairwise comparison, and a combination of priorities (Malczewski, 1999). In the AHP method, the crucial issue is to develop a hierarchy structure which separates the problem into a hierarchy of goal, main-criteria, and sub-criteria. Constructing the hierarchy structure is a fundamental process of the AHP method (Taherdoost, 2017). The mathematical process of the method has been presented in Figure 1 .

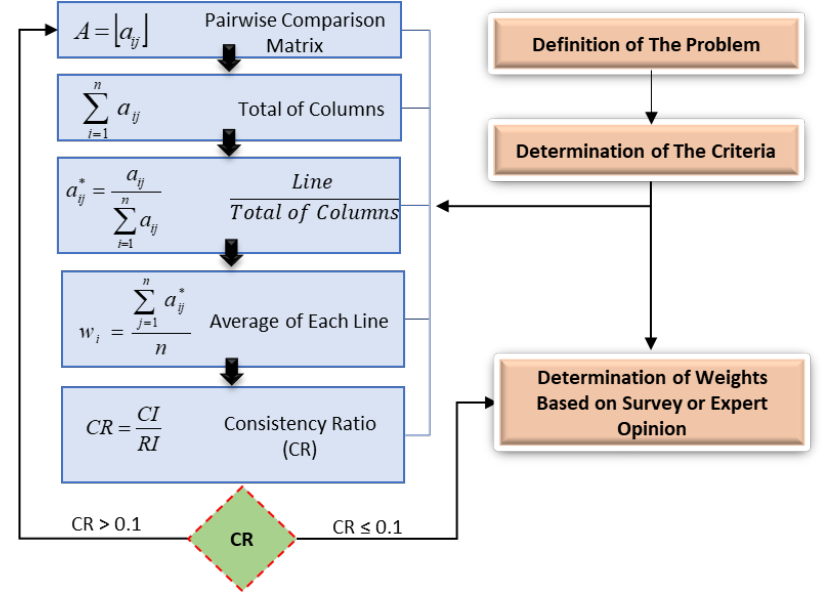

Figure 1. AHP method process flow diagram

Despite the advantages of the AHP method, this method is criticized for its inadequate to overcome the uncertainty observed in the decision-making process that results in uncertain value judgments of decision-makers using the traditional AHP approach (Mosadeghi et al., 2013). On the other hand, the FAHP method has been developed to deal with these disadvantages of AHP and it is used frequently beside the traditional AHP method. FAHP is both an alternative approach to traditional AHP and is quite similar to it. However, the first point where these two methods differ basically is the development of pairwise comparison matrices, and Table 1 is used when developing these matrices (Soberi and Ahmad, 2016). FAHP addresses the fuzziness and vagueness in the preference judgments of decision-makers (Ustaoglu and Aydinoglu, 2020).

\begin{tabular}{ccc}
\hline $\begin{array}{c}\text { Saaty } \\
\text { scale }\end{array}$ & $\begin{array}{c}\text { Triangular } \\
\text { fuzzy scale }\end{array}$ & Definition \\
\hline 1 & $(1,1,1)$ & Equally important \\
3 & $(2,3,4)$ & Weak \\
5 & $(4,5,6)$ & Fairly strong \\
7 & $(6,7,8)$ & Very strong \\
9 & $(9,9,9)$ & Absolutely more important \\
2 & $(1,2,3)$ & \\
4 & $(3,4,5)$ & The intermittent values between \\
& two scales \\
6 & $(5,6,7)$ & \\
\hline & $(7,8,9)$ & \\
\hline
\end{tabular}

Table 1. The scales used to develop a pairwise comparison matrix in AHP and FAHP techniques

Another MCDA technique commonly used in the literature is Fuzzy Logic. This approach was developed by Zadeh in 1965. Zadeh defined a fuzzy set as a class of objects with a continuum grade of memberships and used different functions with memberships. The fuzzy logic technique has the advantage that each element in a fuzzy set can have a value between 0 and 1 , as on the contrary to 0 or 1 , as in classic set theory. That is to say, a fuzzy set object may be a full member or partial member and the assigned membership value of an object is not limited to 0 or 1 (Nedeljkovic, 2006). In fuzzy logic approach, fuzzy sets are formulated as in Equation 1.

$A=\left\{\left(x, \mu_{A}(x)\right) \mid x \varepsilon X\right\}$

where the $\mu A(x)$ is membership function and is known as the degree of membership of $\mathrm{x}$ in A. Generally, $\mu A(x)$ is a number 
within the range $0-1$, where 0 denotes no membership, and 1 denotes full membership (Chaira, 2019 and Zadeh, 1965). The membership functions may have various shapes and can be noncontinuous- non-linear, symmetrical-asymmetrical. A basic membership function is a triangular form, but there are other function forms such as sigmoid, inverted sigmoid, gaussian, and linear. These functions can vary to application requirements (Ustaoglu and Aydınoglu 2020). In addition, the Fuzzy logic approach is a highly effective approach that can be used both alone and integrated with other MCDA methods such as AHP and FAHP, etc. The technique has found to itself a wide range of applications in the literature, from land suitability assessment for different facilities to providing land value information. In this respect, it is one of the outstanding methods of GIS-based MCDA techniques that can be used in different applications within the management of smart cities.

WLC is an analytical MCDA technique that can be used when overcoming decision making or when more than one parameter must be taken into consideration. WLC is based on the concept of a weighted average in which continuous parameters are normalized to a common numeric range and then combined with a weighted average (Drobne and Lisec, 2009). WLC is used generally with GIS and also it is known as simple additive weighting, weighted summation, weighted linear average, and weighted overlay (Malczewski, 2006). In WLC, the total score for each decision alternative is calculated by multiplying the importance weight coefficient assigned to each criterion by the scaled value given for that attribute to the decision alternative and then summing the outputs over all attributes. In other words, WLC is a map combination process that associates with the decision alternatives a set of criterion weights and combines the weights with the attribute (criterion) values (Malczewski and Rinner, 2015). The mathematical equation of the techniques is expressed by Equation 2.

$$
S=\sum_{j=1}^{n} \mathcal{W}_{i} \boldsymbol{x}_{i}
$$

Where $S$ is the total score for each decision alternative; $n$ is the number of parameters considered in the decision or analysis and $W_{i}$ is the weight of criterion $i$ which can be calculated by using such the AHP, FAHP methods and $X_{i}$ is the factor score of criterion $i$. Besides this technique is especially used in GISbased land suitability assessment, it can be used effectively for various smart city applications.

TOPSIS, another MCDA technique, frequently used in the literature was first introduced by Hwang and Yoon in 1981. This technique allows for a priority ranking by evaluating alternative decision options according to certain criteria. The main principle of the technique can be expressed as choosing the alternative decision closest to the positive ideal solution and the most distant to the negative ideal solution as seen in Figure 2 (Tzeng and Huang, 2011; Beskese et.al., 2015; Balioti et.al., 2018).

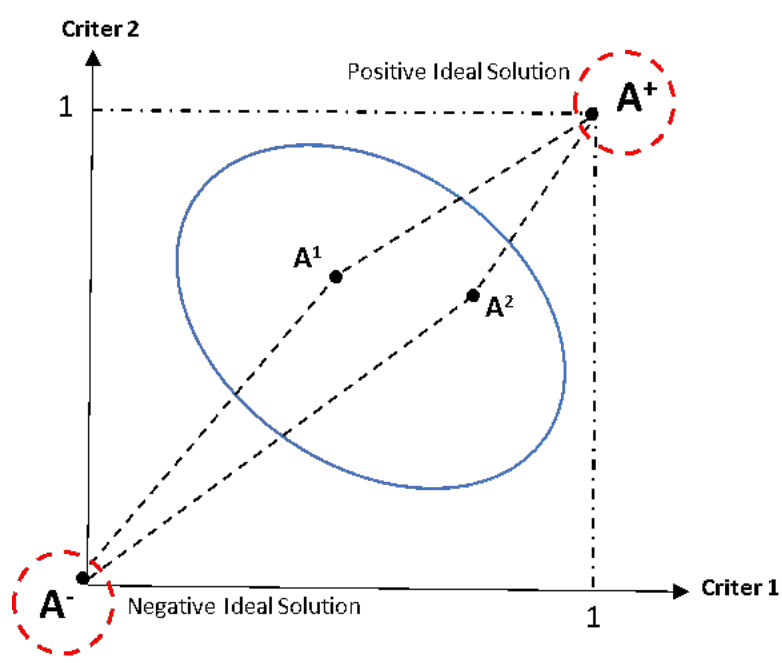

Figure 2. The main idea of TOPSIS technique

TOPSIS is an easy method to understand and interpret because it does not include mathematical expressions and complex algorithms and can work integrated with different MCDA techniques (Behzadian et al., 2012; Darani et al., 2018). The process steps of the method have been presented in Figure 3.

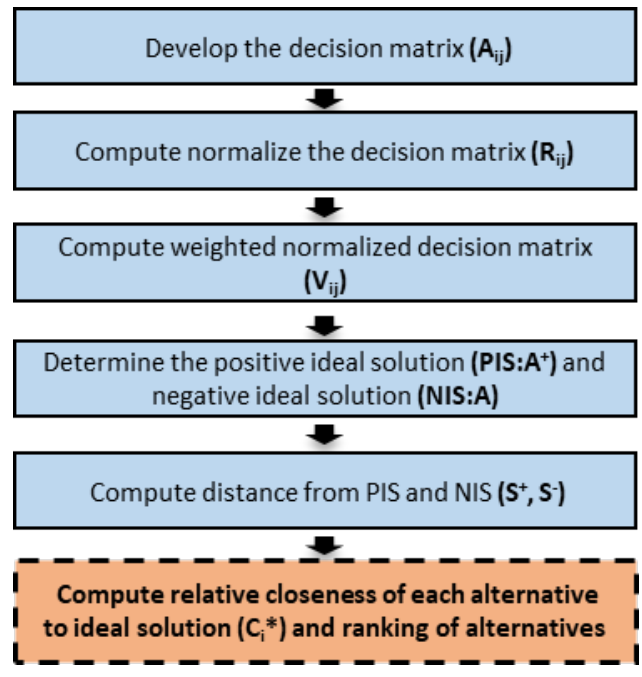

Figure 3. TOPSIS process steps

There is another MCDA technique similar to TOPSIS and it is known as VIKOR technique. VIKOR was developed by Serafim Opricovic in 1998 for the solution of clash decision problems, which conflict with each other and consist of criteria in different units (Opricovic, 1998). In this method, it allows a ranking or prioritizing for alternative decision points as in TOPSIS. The VIKOR method aims to determine a compromised ranking and achieve a compromised solution under the specified weights. The compromise solution is to reach an agreement on all the parameters that are optimally achieved and joint acceptance. On the other hand, the compromise solution is the closest to the ideal solution as in TOPSIS. VIKOR ranks alternatives and determines the solution named compromise that is the closest to the ideal. VIKOR method can be integrated with various MCDA techniques such as the TOPSIS method. The VIKOR method implement process consists of the steps in Figure 4 (Opricovic and Tzeng, 2004; Mohaghar et.al., 2012). 


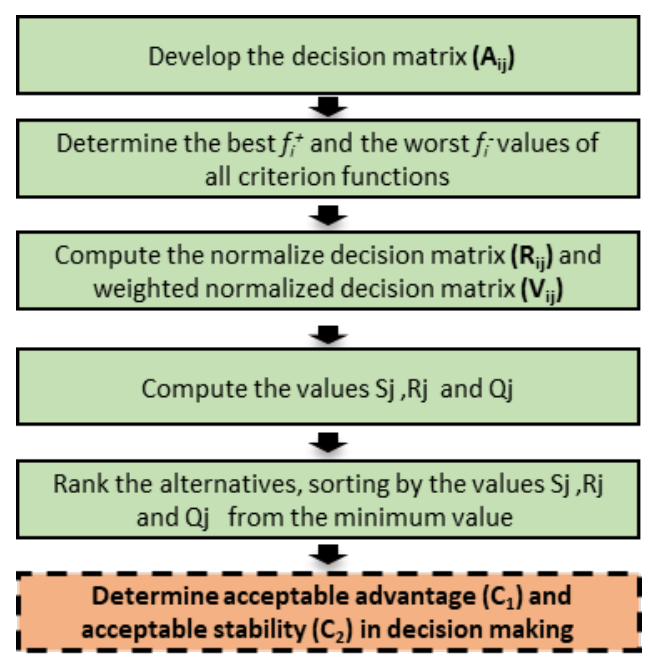

Figure 4. VIKOR process steps

\section{CASE APPLICATIONS}

In this section, different and illustrative case studies for GISbased MCDA techniques that can be used in smart cities have been given below. Some of these case studies were performed previously and published in various academic journals, some were performed within this study.

Ustaoglu and Aydınoglu (2020) used different MCDA techniques together such as AHP, FAHP, and Fuzzy Logic (with different fuzzy membership functions), WLC and GIS techniques for suitability assessment of urban construction land in Pendik district of Istanbul, Turkey. Firstly, they determined the land suitability criteria for urban development based on literature. Then they developed a hierarch structure that consists of main and sub-criteria. The main criteria are physical attributes, accessibility, blue and green amenities, built-up area, vegetation, and geology. The main criteria have different number of sub-criteria and these criteria are distance to somewhere (metro stations, coastline, etc.), slope, aspect, elevation, land use, and soil capacity. For determined criteria, various geographic analysis were performed with GIS. They used two approaches as deterministic and fuzzy model. In the deterministic model, they used the AHP method to weight main and sub-criteria. They applied the process in Figure 1 for AHP and obtained weights. Then, these weights were used with the WLC method and calculated suitability index for residential, industrial/commercial, recreational in the Pendik district. Results map has been presented for residential land suitability in Figure 5. In the fuzzy model, FAHP, Fuzzy logic, and WLC methods were used. Similar processes were performed to the deterministic model and were obtained close results. The use of MCDA and GIS as in this study is an example of any land suitability evaluation study that can be performed in smart cities.

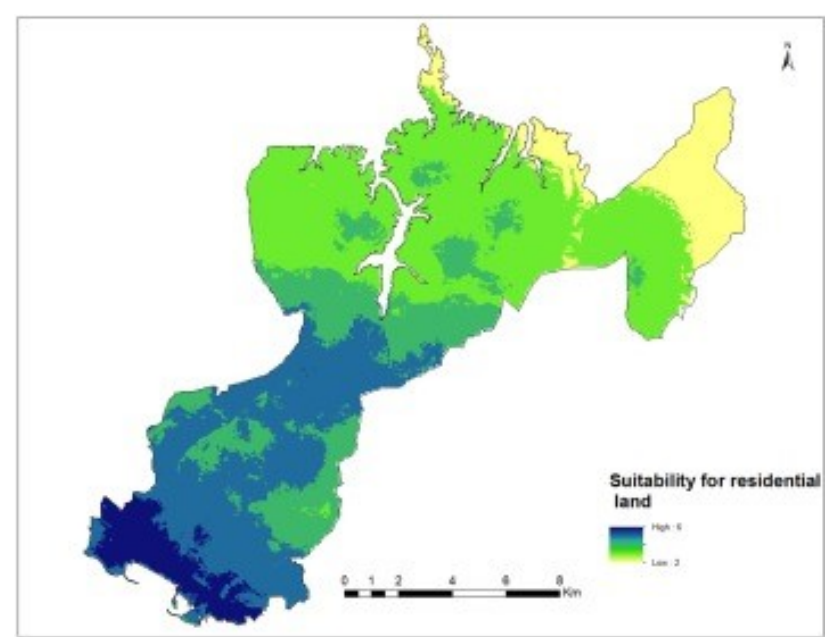

Figure 5. Residential land suitability for Pendik/Istanbul

Bovkir and Aydinoglu (2018) used geographical analysis techniques and Fuzzy Logic with fuzzy memberships and WLC techniques to provide reliable land value information in urban areas. The case application was implemented in the Pendik district of Istanbul. They firstly defined criteria that affect the value of the land, based on the literature, as in the case study above. These criteria were grouped as legal/ planning factors, public services, environmental/ utilization factors, transportation, and socio-cultural factors. These groups have various sub-criteria. Then, different and suitable fuzzy memberships (gaussian, linear, sigmoidal, etc.) in the fuzzy logic approach were determined for each group of criteria and related sub-criteria. Fuzzy memberships were used based on GIS. For above mentioned each of the criteria groups fuzzy value maps were produced and also they can be thought of as group indexes. These fuzzy group maps provide precious and important information with regard to land management applications in the smart cities. Thereafter, fuzzy group maps were combined with WLC techniques. In WLC, weights were used with the literature-based AHP technique. In this manner, a land value map was produced for the Pendik district. The final map has been presented in Figure 6. This value map is quite reliable and accurate besides it includes information from different data sources.

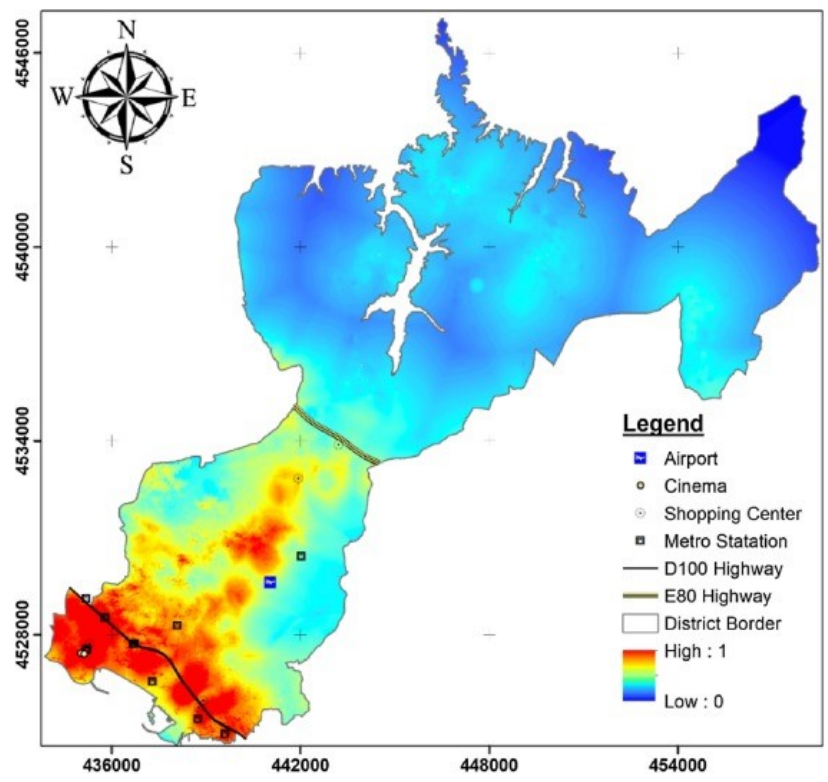

Figure 6. Land value map for Pendik district 
In this study proposed GIS-MCDA model provides a different perspective of urban land management thanks to hybrid use. The model supports information sharing with e-government applications, as well as constituting a basis for different real estate management applications in smart cities. This study provides an innovative procedure with a case study for real estate management in model-smart cities.

Iqbal and Aydinoglu (2019) used the AHP and WLC technique based on GIS for vehicle parking site selection that is a very important issue for urban transportation. As in the case studies above, the study area of this study is the Pendik district of Istanbul. Similarly to the above cases, firstly was determined criteria that affect site selection base on literature and expert's opinions. For AHP technique constructed a hierarch structure that consists of 3 main criteria group (transportation, parking and travel absorption) and 18 sub-criteria (proximity to existing parking areas, proximity to public transportation stops, traffic volume, number of vehicles, land cost, etc.). To determine the weights of the main and sub-criteria were performed a survey study to expert persons in transportation. Then, for AHP was developed pairwise comparison matrixes ( 1 matrix for main criteria groups and 3 matrices for sub-criteria) and were calculated weight of criteria. Criteria affecting vehicle site selection were analysed such as distance, slope, aspect, density etc., with different GIS analysis techniques. By using AHP weights with the WLC method, suitable car parking sites for the Pendik district were determined based on GIS. The obtained final car parking suitability map has been presented in Figure 7. This study provides an example approach that can be easily in practice applied for sustainable urban transportation planning in the concept of smart cities.

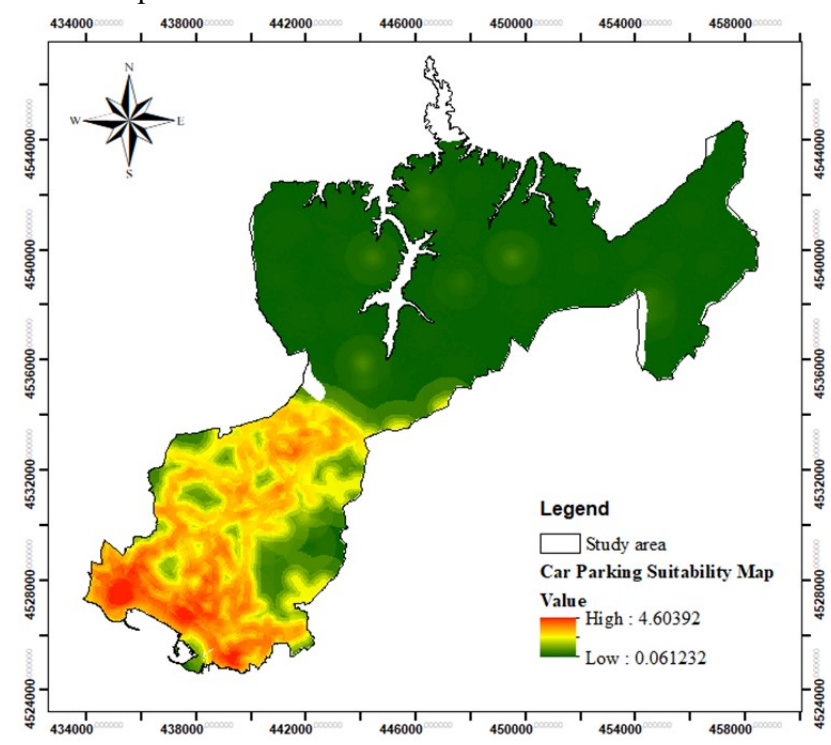

Figure 7. Car parking site selection application in Pendik/Istanbul

Advanced of this site selection study is the priority ranking of the determined suitable/alternative parking areas. For this purpose, TOPSIS and VIKOR techniques, which are among the MDCA methods described in section 2 and used for ranking, can be used with AHP. For the implementation of TOPSIS and VIKOR techniques, the process in Figure 3 and Figure 4 is followed. In the application, the results of which have been presented in Figure 8 and which is a continuation of the parking site selection study, alternative/suitable car parking areas were ranked using AHP and TOPSIS techniques. Firstly, locations of suitable parking areas were determined by taking into account high suitable values in the zoning plans. Thus, 11 of parking areas with high parking suitable values were determined in the Pendik district of Istanbul. In Figure 8, suitable parking alternatives have been shown as $A_{1}, A_{2}, \ldots A_{11}$. Then, for these alternative car parking areas, the decision matrix (different from AHP) was developed based on expert's opinions and literature with 18 criteria.

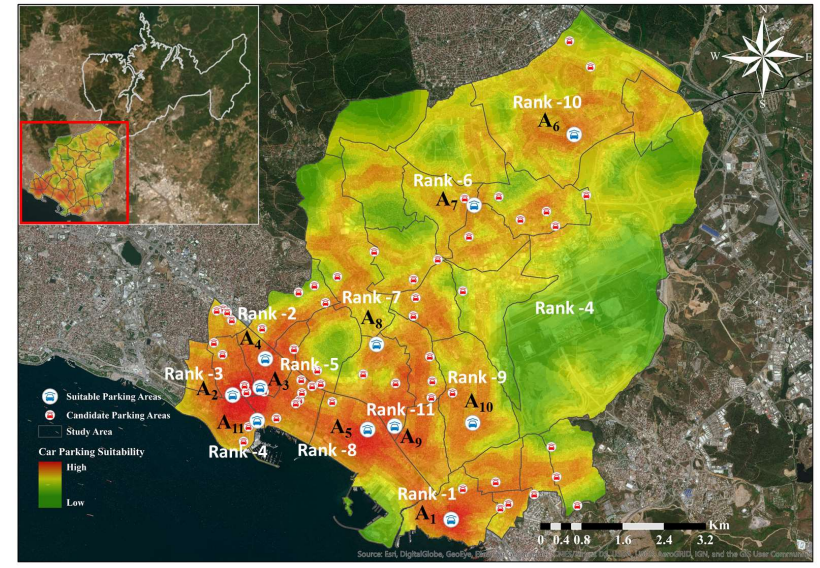

Figure 8. Ranking alternative car parking areas for Pendik / Istanbul

Then mentioned above AHP weights were used integrated with TOPSIS. By performing the methodology of the TOPSIS method, 11 alternative parking lots were prioritized within themselves. Ranking results have been presented in Figure 9.

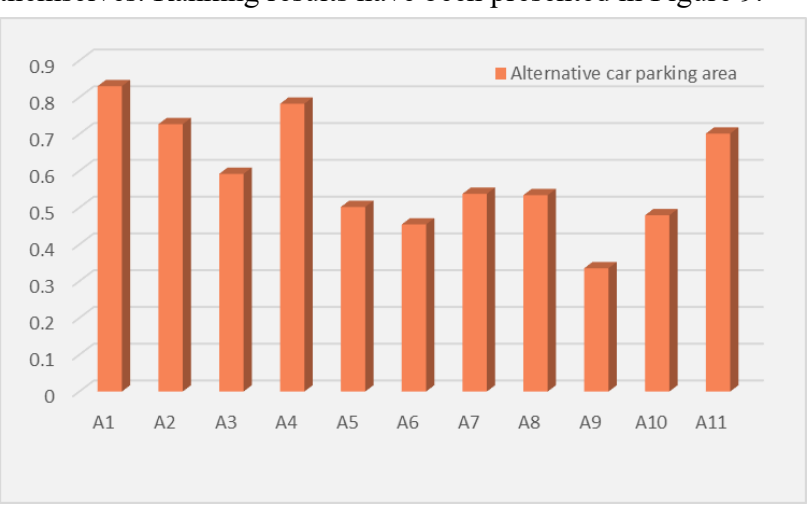

Figure 9. Result of ranking alternative car parking areas by TOPSIS technique

The GIS-based hybrid use of different MCDA techniques proposed in this case study is an example for many applications in smart cities. The proposed approach can be used as a geographic decision support system for different decision problems in smart cities as well as being used in different site selection studies.

\section{DISCUSSION}

Cities are rapidly getting crowded day by day, and it has become essential to make effective decisions in various application areas, from transportation to energy, from land management to the location selection of urban services. In order to provide more liveable and sustainable urban areas and to increase the quality of urban life, many decision factors in urban management should be considered rationally with a holistic perspective. 
When it is necessary to make a decision in cities, it is required to analyze different geographical data from different sources and to solve complex decision problems, the groups of criteria that affect the decision and the effect of these groups subcomponents should be well defined. When necessary, expert opinions and academic studies should be taken into consideration. In this sense, while GIS techniques provide the opportunity to analyse geographical data by processing, MCDA techniques offer various approaches to geographic analysis with the help of mathematical algorithms with GIS.

Although many MCDA techniques mentioned have been used in practice, in this study AHP, FAHP, TOPSIS, VIKOR, and Fuzzy Logic techniques were examined as decision support mechanisms in smart cities with GIS technologies. As a result of the assessments made with the opinions of the relevant people and the literature for the selection of any facility location to be carried out on an urban scale, the AHP technique is foremost in determining the relative weights of the criteria. The AHP can be used in specific workspaces such as real estate valuation and urban planning, as well as the site selection for public service areas such as car parking areas, shopping malls, schools, and hospitals, etc. The fuzzy logic approach is the outstanding MCDA technique in evaluating any criterion or criteria group with continuous and sharply unconstrained curves in contrast to those defined in sharp criteria groups. Besides being used in many different urban applications, it is very advantageous in evaluating small criteria groups (with fuzzy overlay). For example, the urban accessibility index can be produced by evaluating different public transportation systems such as metro, bus, railway, the airport in a city with appropriate GIS-based fuzzy membership functions in the fuzzy logic method. This example can be expanded in the context of smart cities and contribute to urban management by producing different index values such as health index, education index, social life index for a city.

If the issue is the ranking or prioritizing in the multi-criteria decision-making problems, the notable MCDA approaches are TOPSIS and VIKOR techniques. These techniques can be used in integration with GIS technologies and AHP to contribute to urban management in smart cities for different decision problems. For instance, with the hybrid use of these methods, investment projects to be carried out by local government authority in a city can be prioritized and the most appropriate investment project can be determined, saving time and cost.

In summary, the hybrid use of MCDA techniques contributes to the authority administrators for the realization of various smart city applications. GIS-based and hybrid use of various MCDA techniques for different applications with quite different decision scenarios provides effective decision support mechanisms on the basis of smart cities. Namely, we recommend using different GIS-based MCDA techniques as hybrid approaches according to application needs. For example, it was explained how AHP can be used with Fuzzy based techniques in the Residential Land Suitability case study. In addition, other MCDA techniques should be performed and can be tested with the proposed approaches.

\section{REFERENCES}

Balioti, V., Tzimopoulos, C., \& Evangelides, C. 2018. Multicriteria decision making using topsis method under fuzzy environment. Application in spillway selection. In Multidisciplinary Digital Publishing Institute Proceedings (Vol. 2, No. 11, p. 637).
Behzadian, M., Otaghsara, S. K., Yazdani, M., \& Ignatius, J. 2012. A state-of the-art survey of TOPSIS applications. Expert Systems with applications, 39(17), 13051-13069.

Beskese, A., Demir, H. H., Ozcan, H. K., \& Okten, H. E. 2015. Landfill site selection using fuzzy AHP and fuzzy TOPSIS: a case study for Istanbul. Environmental Earth Sciences, 73(7), 3513-3521.

Bovkir, R., \& Aydinoglu, A. C. 2018. Providing land value information from geographic data infrastructure by using fuzzy logic analysis approach. Land use policy, 78, 46-60.

Chaira, T. 2019. Fuzzy Set and Its Extension John Wiley \& Sons, USA.

Cinelli, M., Coles, S. R., \& Kirwan, K. 2014. Analysis of the potentials of multi criteria decision analysis methods to conduct sustainability assessment. Ecological indicators, 46, 138-148.

Darani, S. K., Eslami, A. A., Jabbari, M., \& Asefi, H. 2018. Parking lot site selection using a fuzzy AHP-TOPSIS framework in Tuyserkan, Iran. Journal of Urban Planning and Development, 144(3). https://doi.org/10.1061/(ASCE)UP.19435444.0000456

De Montis, A., De Toro, P., Droste-Franke, B., Omann, I., \& Stagl, S. 2000. Criteria for quality assessment of MCDA methods. In 3rd Biennial Conference of the European Society for Ecological Economics, Vienna (pp. 3-6).

Drobne, S., \& Lisec, A. 2009. Multi-attribute decision analysis in GIS: weighted linear combination and ordered weighted averaging. Informatica, 33(4).

Huang, I. B., Keisler, J., \& Linkov, I. 2011. Multi-criteria decision analysis in environmental sciences: Ten years of applications and trends. Science of the total environment, 409(19), 3578-3594.

Hwang, C. L., \& Yoon, K. 1981. Multiple criteria decision making. Lecture Notes in Economics and Mathematical Systems, 186, 58-191.

Iqbal A.S., Aydinoglu A.C. 2019. Determining Parking Demand By The Integration of Geographic Information System (GIS) and Analytical Hierarchy Process (AHP), International Symposium on Applied Geoinformatics (ISAG-2019), İstanbul, Turkey

Malczewski, J. W. 1999. GIS and Multi Criteria Decision Analysis. In Computers \& Geosciences (1st ed., Vol. 26, p. 392)

Malczewski, J. 2006. GIS-based multicriteria decision analysis: a survey of the literature. International journal of geographical information science, 20(7), 703-726.

Malczewski, J. 2010. Multiple criteria decision analysis and geographic information systems. In Trends in multiple criteria decision analysis (pp. 369-395). Springer, Boston, MA.

Malczewski, J., \& Rinner, C. 2015. GIScience, Spatial Analysis, and Decision Support. In Multicriteria Decision Analysis in Geographic Information Science (pp. 3-21). Springer, Berlin, Heidelberg. 
Malczewski, J., \& Rinner, C. 2015. Multiattribute decision analysis methods. In Multicriteria Decision Analysis in Geographic Information Science (pp. 81-121). Springer, Berlin, Heidelberg.

Mardani, A., Jusoh, A., Nor, K., Khalifah, Z., Zakwan, N., \& Valipour, A. 2015. Multiple criteria decision-making techniques and their applications-a review of the literature from 2000 to 2014. Economic Research-Ekonomska Istraživanja, 28(1), 516571.

Mohaghar, A., Fathi, M. R., Zarchi, M. K., \& Omidian, A. 2012. A combined VIKOR-fuzzy AHP approach to marketing strategy selection. Business Management and Strategy, 3(1), 13.

Mosadeghi, R., Warnken, J., Tomlinson, R., \& Mirfenderesk, H. 2013. Uncertainty analysis in the application of multi-criteria decision-making methods in Australian strategic environmental decisions. Journal of Environmental Planning and Management, 56(8), 1097-1124.

Nădăban, S., Dzitac, S., \& Dzitac, I. 2016. Fuzzy topsis: A general view. Procedia Computer Science, 91, 823-831.

I. Nedeljkovic 2006. Image classification based on fuzzy logic Remote Sens. Spatial Inform. Sci., 34 (2006), pp. 1-6

Nyimbili, P. H., \& Erden, T. 2020. A Hybrid Approach Integrating Entropy-AHP and GIS for Suitability Assessment of Urban Emergency Facilities. ISPRS International Journal of Geo-Information, 9(7), 419.

Opricovic, S. 1998. Multicriteria optimization of civil engineering systems. Faculty of Civil Engineering, Belgrade, 2(1), 5-21.

Opricovic, S., \& Tzeng, G. H. 2004. Compromise solution by MCDM methods: A comparative analysis of VIKOR and TOPSIS. European journal of operational research, 156(2), 445-455.

Saaty, T. L. 1980. The Analytic Hierarchy Process Mcgraw Hill, New York. Agricultural Economics Review, 70.

Soberi, M. S. F., \& Ahmad, R. 2016. Application of fuzzy AHP for setup reduction in manufacturing industry. J. Eng. Res. Educ, 8, 73-84.

Taherdoost, H. 2017. Decision making using the analytic hierarchy process (AHP); A step by step approach. International Journal of Economics and Management Systems, 2.

Tzeng, G. H., \& Huang, J. J. 2011. Multiple attribute decision making: methods and applications. CRC press

Ustaoglu, E., \& Aydınoglu, A. C. 2020. Suitability evaluation of urban construction land in Pendik district of Istanbul, Turkey. Land Use Policy, 99, 104783.

Wang, G., Qin, L., Li, G., \& Chen, L. 2009. Landfill site selection using spatial information technologies and AHP: a case study in Beijing, China. Journal of environmental management, 90(8), 2414-2421.
Zadeh, L. A. 1978. Fuzzy sets as a basis for a theory of possibility. Fuzzy sets and systems, 1(1), 3-28. 